УДК 372.016:811.111+ 811.111’342

ПРИМЕНЕНИЕ ИНФОРМАТИВНО-КОММУНИКАЦИОННЫХ ТЕХНОЛОГИЙ ДЛЯ СОВЕРШЕНСТВОВАНИЯ ФОНЕТИЧЕСКОЙ КОМПЕТЕНЦИИ У УЧАЩИХСЯ НА УРОКАХ АНГЛИЙСКОГО ЯЗЫКА

Гахраманова Р.И., Кургулова В.К.

Новосибирский Государственный Педагогический Университет

Новосибирск, Россия

В данной статье рассмотрен вопрос о применение информационно - коммуникационных технологий для совершенствования фонетической компетенции учащихся на уроках английского языка. Рассматривается понятие фонетической компетенции, как одна из важнейших частей иноязычной коммуникативной компетенции. А именно, социокультурный компонент фонетической компетенции, так как он включает в себя знания и умения использования особенностей произношения на основе сравнительно-сопоставительного анализа фонетических систем родного и иностранного языка. В статье представлены результаты апробации комплекса упражнений для совершенствования фонетической компетенции у школьников, на уроках английского языка, через использование платформ информационно-коммуникационных технологий lingt.com и manythings.org, а также показано, что комплекс разработанных авторами статьи уроков является эффективным средством для совершенствования фонетической компетенции при применении их на уроках английского языка.

Ключевые слова: фонетическая компетенция, информационно - коммуникационных технологии, платформы ИКТ, комплекс упражнений.

\title{
THE USE OF INFORMATION AND COMMUNICATION TECHNOLOGIES FOR IMPROVING STUDENTS' PHONETIC COMPETENCE IN ENGLISH LESSONS IN A SECONDARY SCHOOL
}

Rabina I. Gakhramanova, Viktoriya K. Kurgulova

Novosibirsk State Pedagogical University

Novosibirsk, Russia

The article is devoted to the use of information and communication technologies for improving students' phonetic competence in English lessons in a secondary school. The authors reveal the concept of phonetic competence, as one of the main parts of the foreign language communicative competence. Especially, a socio-cultural component because it includes knowledge and skills of using features of pronunciation based on the comparative analysis of phonetic systems of native and foreign languages. The authors analyze the approbation of a set of exercises for improving students' phonetic competence in English lessons in a secondary school through Information and communication technology platforms linght.com and manythings.org and show the effectiveness of a set of lessons designed to improve the students' phonetic competence in English lessons.

Keywords: phonetic competence, information and communication technologies, ICT platforms, a set of lessons.

Процесс информатизации общества предъявляет новые требования к профессиональным качествам учителя в области использования средств ИКТ. Использование информационно - коммуникативных технологий на уроках английского языка - это необходимое условие и механизм реализации ФГОС. В процессе изучения всех школьных 
предметов должны широко использоваться различные источники информации, в число которых входит Интернет.

Использование ИКТ на уроках английского языка позволяет организовать самостоятельные действия каждого ученика и реализовать его творческий потенциал [2].

Каждый урок иностранного языка должен быть направлен на практический результат, на достижение коммуникативной компетентности, т.е., определенного уровня языковых, страноведческих знаний, коммуникативных умений и речевых навыков, позволяющих осуществлять иноязычное общение, то есть формирование иноязычной коммуникативной компетенции (ИКК). Среди субкомпетенций ИКК особое место занимает фонетическая компетенция.

Хомутова А.А. определяет фонетическую компетенцию как основанную на знаниях, умениях, навыках и отношениях способность индивида осуществлять иноязычную коммуникативную компетенцию в соответствии с произносительными нормами изучаемого языка [6].

Коррекция произношения очень важна на любом этапе обучения, так как любой язык - это звуковая система, и если нарушать фонетические нормы языка, то частично или полностью нарушится информативность. Недаром, известный русский лингвист Бернштейн С.И. сказал: «Учащиеся воспринимают звучание чужой речи сквозь призму фонетической системы родного языка. Обладая устойчивыми навыками слышания и произнесения звуков родного языка, они подгоняют под эти шаблоны свое восприятие и воспроизведение непривычных звуков чужой речи» [1]. В свою очередь Трубецкой Н.С. подчеркивал, что иностранный акцент зависит совсем не от того, что иностранец не в состоянии произнести тот или иной звук, а скорее от того, что он «неверно судит об этом звуке», что обусловлено фонологическими системами иностранного и родного языка [5].

Внедрением платформ ИКТ в процессе обучения английскому языку активно занималась доктор педагогических наук, профессор Е. С. Полат. Она является автором исследований по обучению иностранным языкам, методу проектов, использованию Интернет - технологий и ресурсов в системе образования [4].

Проблемы внедрения ИКТ на уроках иностранного языка рассматривались так же в работах Коптюг Н. М. [3].

ИКТ технологии на уроках английского языка являются эффективным педагогическим средством изучения иноязычной культуры и формирования коммуникативных навыков. Необходимо заметить, что применение ИКТ способствует ускорению процесса обучения, росту интереса учащихся к предмету, улучшают качество усвоения материала, позволяют индивидуализировать процесс обучения и дают возможность избежать субъективности 
оценки. Уроки иностранного языка с использованием ИКТ отличаются разнообразием, повышенным интересом учащихся к иностранному языку, эффективностью.

В современных источниках информационно-коммуникационные технологии представляют собой широкий спектр цифровых технологий, применяемых для создания, передачи и распространения информации и оказания услуг (компьютерное оборудование, программное обеспечение, телефонные линии, сотовая связь, электронная почта, сотовые и спутниковые технологии, сети беспроводной и кабельной связи, мультимедийные средства, а также Интернет).

Современная образовательная парадигма, строящаяся на компьютерных средствах обучения, берет за основу не передачу школьникам готовых знаний, умений и навыков, а привитие обучающемуся умений самообразования $[7,8]$. При этом работа учащихся на уроке носит характер общения с преподавателем, опосредованного с помощью интерактивных компьютерных программ и аудиовизуальных средств.

В нашем исследовании были использование такие платформы ИКТ, как lingt.com и manythings.org. При помощи данных платформ мы создали комплекс уроков, направленный на коррекцию произносительных навыков учащихся 8 класса.

Проверка эффективности внедрения платформ ИКТ в уроки английского языка происходила на базе Колыванской средней общеобразовательной школы №1 р.п. Колывань. Участниками эксперимента стали ученики 8 класса, изучающие английский язык со 2 класса. Наше исследование состояло из 3 этапов: предэспериментального, экспериментального и постэкспериментального.

Этап предэкспериментального тестирования заключался в оценке сформированности продуктивных фонетических навыков при помощи чтения.

Для проверки уровня сформированности данных навыков при помощи чтения учащимся был предложен для чтения авторский текст бытового характера в количестве 309 знаков.

London is the capital of the United Kingdom. Together with Tokyo and New York is one of the three largest cities in the world. London is situated on the river Thames. It divides the city into north and south. The Londoners call the Thames simply "the river". There are fifteen bridges across the river. The most famous are Westminster, Waterloo, Tower, and London bridges.

Данный текст был специально подобран нами, предусматривая возможные ошибки в произношении английского языка носителями русского языка.

Предэксперимантальный срез проходил на сайте http://lingt.com. Этот сайт был разработан Kim Cofino и Chris Betcher. Он позволяет создавать свои собственные уроки. Учитель может зарегистрироваться на сайте, а затем приступать к созданию урока, используя 
функции, предоставленные на сайте. Данный сайт очень удобен для создания диалога, так как есть возможность звукозаписи. Учителям предоставляется возможность работы с сохраненными записями, комментируя их письменно или с помощью звукозаписи.

Комбинируя все предоставленные возможности сайта, мы создавали наши уроки, а также предэскпериментальный и постэкспериментальный тесты.

Каждый урок состоял из теоретической части, во время которой учащимся открывалось новое знание, и практической части, которая включала в себя отработку пройденного материала на основе упражнений, подобранных нами с использованием ИКТ pecypca manythings.org

Этот сайт был создан Larry Kelly и Charles Kelly в 1997 году для людей, которые изучают английский язык, как дополнительный. Данный сайт не требует регистрации. Для отработки звуков, мы работали с категорией «MINIMAL PAIRS». Также на этом сайте собраны видео с носителем языка с сайта YouTube.com по теме произношение отдельных звуков английского языка. Кроме того, на данной платформе имеются викторины, игры в слова, кроссворды, пословицы и поговорки, которые мы использовали при отработке проблемного звука.

Наш урок включал: скороговорку в текстовом варианте, видео данной скороговорки, произнесенную носителем языка. Ученики просматривали видео и записывали свой голос, далее мы прослушивали записи и выявляли допущенные ошибки в произношении. Записывание скороговорок происходило на дому, в классе мы использовали сайт manythings.org.

Занятия проходили в течение 3 недель, по истечении которых было проведено постэкспериментальное тестирование. Постэксперимантальный срез также проходил на сайте http://lingt.com. На сайте нами был составлен урок с проверочным тестом.

На предэкспериментальном этапе тестирования дети читали текст не очень уверено и с грубыми ошибками в произношении. Средний балл на предэкспериментальном этапе по ошибочным реализациям фонем, который затем был переведен нами в проценты и составлял 78\%. После проведения эксперимента в экспериментальной группе произношение звуков, над которыми мы работали, стало значительно лучше. Подсчитав средний бал по ошибочным реализациям фонем на постэкспериментальном тестирование, который затем был переведен в проценты, мы обнаружили, что он составил $35 \%$.

Сравнив результаты тестирования экспериментальной группы на предэкспериментальном и постэкспериментальном этапе можно констатировать, что после проведения серии уроков, учащиеся стали произносить звуки намного четче и правильнее, 
принимая во внимание положение органов речи при произнесении звуков, которые ранее вызывали трудность в произношении.

Разумеется, данная тема требует дальнейшей последовательной работы для достижения более стабильных и высоких результатов.

Таким образом, мы установили, что результаты, полученные на стадии проведения эксперимента, доказали эффективность разработанных нами уроков по совершенствованию фонетической компетенции у учащихся 8-го класса с использованием платформ ИКТ, что и являлось целью нашей работы.

Список литературы:

1. Бернштейн С.И. Вопросы обучения произношению // Вопросы фонетики и обучение произношению: Сб. науч. тр. - М., 1975. - с.15.

2. Владимирова Л.П. Интернет на уроках иностранного языка // Иностранные языки в школе - 2002. № 3. - С. 33 .

3. Коптюг Н.М. Интернет-уроки как вспомогательный материал для учителя английского языка. Журнал “Иностранные языки в школе”, 2000, № 4.

4. Полат Е.С. Метод проектов на уроках иностранного языка/ Иностранные языки в школе - № № 2, 3 - 2000 г.

5. Трубецкой Н.С. Основы фонологии. - М.: Высшая школа, 1960. - 372

6. Хомутова А.А. Формирование фонетической компетенции на основе мультимедиа (английский язык, языковой вуз): автореф. дис. канд. пед. наук. - Тамбов, 2007 - 21с.

7. Хорошилова С.П. Компетентностный подход в преподавании практической фонетики английского языка в педагогическом вузе // Проблемы и перспективы развития образования в России. - 2010. - № 4-2. - с. 35-40.

8. Хорошилова С.П. Фонетика английского языка: Продвинутый уровень: учебнометодическое пособие / Новосибирск, 2015. 